\title{
Atmospheric structures in the troposphere as revealed by high-resolution backscatter images from MU radar operating in range- imaging mode
}

\author{
Lakshmi Kantha ${ }^{1}$, Hubert Luce ${ }^{2}$, Hiroyuki Hashiguchi ${ }^{3^{*}}$ (1) and Abhiram Doddi ${ }^{1}$
}

\begin{abstract}
VHF band stratosphere/troposphere (ST) radars around the globe are seldom operated in range-imaging mode. As such, the typical range resolution of their backscatter images is about $150 \mathrm{~m}$. The only exception is the Kyoto University's Middle and Upper Atmosphere (MU) radar in Shigaraki, Japan. Range imaging using frequency diversity was implemented there in 2005 and has often been used since then. During the Shigaraki UAV Radar Experiment (ShUREX) campaigns in the spring/summers of 2015, 2016, and 2017, the MU radar was operated in range-imaging mode to provide a range resolution of typically $20 \mathrm{~m}$, for good signal to noise (SNR) ratios. The resulting Capon backscatter images revealed a variety of atmospheric structures in the moist troposphere in great detail. They were also quite useful in deploying in situ sensors on board unmanned aerial vehicles (UAVs) to probe such structures in near real time guided by the images. The goal of this paper is to present and discuss some such structures of interest to atmospheric dynamics collectively, to provide an overarching view. They include Kelvin-Helmholtz (KH) billows generated by shear instability, mid-level cloud-base turbulence (MCT) layers generated by convective instability in a moist troposphere, convective boundary layer (CBL), and sheet and layer (S\&L) structures in a stably stratified atmospheric column. Videos of radar images collected during the 2015 and 2016 campaigns are included as Additional files 1, 2 and 3 with a brief explanatory text as Additional file 4 to demonstrate the fascinating, everchanging evolution of atmospheric structures over the MU radar.
\end{abstract}

Keywords: VHF radar, MU radar, Range-imaging mode, Unmanned aerial vehicles, UAV, Turbulence kinetic energy, TKE, TKE dissipation rate, Stably stratified flows, Troposphere, Moist troposphere, Convective boundary layer, Midlevel cloud-base turbulence, MCT, Sheet and layer structures

\section{Introduction}

The Middle and Upper atmosphere (MU) radar is a Doppler-pulsed VHF radar operating at $46.5 \mathrm{MHz}(6.45$ $\mathrm{m}$ radar wavelength, $3.5 \mathrm{MHz}$ bandwidth and $1 \mathrm{MW}$ peak output power). It is located at Shigaraki, Japan $\left(34.854061^{\circ} \mathrm{N}, 136.105606^{\circ} \mathrm{E}\right), 378 \mathrm{~m}$ above sea level (ASL). During the Shigaraki UAV Radar Experiment (ShUREX) campaigns, the radar was operated in range-imaging mode, using frequency diversity (called FII by Luce et al. 2001) at vertical incidence in 2015 and

\footnotetext{
* Correspondence: hasiguti@rish.kyoto-u.ac.jp

${ }^{3}$ Research Institute for Sustainable Humanosphere, Kyoto University, Kyoto, Japan

Full list of author information is available at the end of the article
}

three directions in 2016 and 2017, using five closely spaced frequencies between 45.0 and $47.0 \mathrm{MHz}$ switched pulse to pulse, resulting in a high vertical resolution of $\sim 20 \mathrm{~m}$ typically, compared to $\sim 150 \mathrm{~m}$ in the normal operational mode. Under normal operation (non-range-imaging mode), five principal beams, one zenith, and four $10^{\circ}$ off zenith (north, south, east, and west) are used, all at $46.5 \mathrm{MHz}$ frequency. In the range-imaging mode, because the radar controller system imposes that the number of beams must be a multiple of the frequency number used, a total of 10 or 15 beams was programmed: five different frequency $(45.0,45.5,46.0,46.5$, $47.0 \mathrm{MHz}$ ) beams along the zenith and along one or two other off -zenith directions (east in 2015 and east and 
north in 2016) were used. Luce et al. (2018a) have demonstrated that the high-resolution Capon images that range imaging produces are devoid of any "ghosts," and therefore, the atmospheric features visible in the images are real. Therefore, the fine structures revealed by range imaging, such as the sheet and layer (S\&L) structures (see below), are not spurious. This point is essential to the wide-spread acceptance and use of range imaging in routine operations of ST radars around the world.

\section{Methods/Experimental}

During all three campaigns (ShUREX 2015, 2016, and 2017), the UAV DataHawk, developed by Prof. Dale Lawrence at the University of Colorado, was flown near and above the radar to gather simultaneous data from the radar and from in situ sensors on the UAV, guided in real time by radar images. Radiosondes were also launched occasionally. The focus of the campaigns was measurement of turbulence in the lower troposphere. However, the resulting rich dataset also contains examples of a variety of atmospheric structures, which will be discussed in the next section. More details about the ShUREX campaign can be found in Kantha et al. (2017) and Luce et al. (2018a, b, c, d). An earlier campaign at Shigaraki called Tanuki 2011 (Wilson et al. 2014) also gathered high-resolution Capon images, but those will not be discussed here.

The goal of this paper is to present and discuss structures of interest to atmospheric dynamics we saw during ShUREX campaigns collectively, to provide an overarching view. Videos of radar images collected during the 2015 and 2016 campaigns are included as Additional file 1 to demonstrate the evolution of these atmospheric structures far better than one or two still images. To our knowledge, no such high-resolution videos displaying fine-scale atmospheric structures have ever been published. The paper also serves as an introduction to the videos.

\section{Results and discussion \\ Typical atmospheric structures seen during ShUREX campaigns}

The three ShUREX campaigns were conducted during spring/summers of 2015, 2016, and 2017 in the months of May and June, just prior to the onset of the rainy season in Japan. As such, we were able to capture a variety of atmospheric structures in the troposphere and were able to witness their evolution through high-resolution MU radar images. We present and discuss a few of them from the 2015 and 2016 campaigns here. It is important to point out that the dark, thin features seen in MU radar Capon images discussed below and presented in the movies, denote high humidity gradient sheet-like structures, which have high radar reflectivity characteristics. The MU radar provided excellent high-resolution images extending from about $1.34 \mathrm{~km}$ (ASL) to $20 \mathrm{~km}$ (ASL) into the lower stratosphere. However, we will focus here on the troposphere only, since the presence of water vapor in the atmospheric column there gave rise to interesting atmospheric structures including, of course, clouds. In contrast, the atmosphere above $10 \mathrm{~km}$ consisted mostly and almost always of faint sheet and layer (S\&L) structures, described below.

Figure 1 shows S\&L fine-scale structures seen between 09:00 and approximately 17:00 LT during the ShUREX 2015 campaign. These structures consist of visually brighter layers of various depths, bounded by thin, dark sheets. The dark sheets result from strong humidity (and hence refractive index) gradients that affect the backscattered radar signal. Such structures were seen frequently and some persisted for hours (occasionally as long as 24-48 h), before dissipating. We do not see any significant gravity wave activity in Fig. 1. Neither do we see any shear-driven Kelvin-Helmholtz (K-H) instability. So the mechanism responsible for the generation (and dissipation) of such fine-scale structures is not clear, to us anyway. The top of the convective boundary layer (CBL) indicated by the dark sheet at an altitude (ASL) of about $2 \mathrm{~km}$, with associated convective plume activity, can be seen throughout the period. A high degree of chaotic activity can also be seen inside the clouds above $6-7 \mathrm{~km}$ ASL (above the sheet-like structures).

Figure 2 shows the Capon image on June 30, 2016, from 12:00 to 18:00 LT during the ShUREX 2016 campaign. Intrusion of a dry but warm air mass over the colder, but moist, nearly saturated layer adjacent to the ground around 09:00 LT triggered the formation of the structure seen in the figure between roughly 3 and $4 \mathrm{~km}$ ASL. A radiosonde was launched at 14:58 LT, and the UAV itself carries temperature and humidity sensors, which confirm the existence of warm, dry (2\% RH) airmass above the colder, moist (98\% RH) airmass. Normally, one would expect the junction between the two air masses (at a height of 3 to $3.5 \mathrm{~km}$ ) to consist of a sharp but stable interface, with a sharp change in humidity and hence refractive index. Therefore, we should see a single dark, strong high humidity gradient sheet. Instead, we see a turbulent "layer" sandwiched between two strong, high humidity gradient "sheets" located at 3 and $3.6 \mathrm{~km}$ altitude at 12:00 LT and extending to 18:00 LT in the figure, both sheets descending slightly and the sandwiched layer decreasing in depth. The upper sheet denotes the top of the moist air mass. The air above this sheet is nearly dry. The relative humidity $(\mathrm{RH})$ decreases from nearly $100 \%$ in the cloudy air mass to nearly $0 \%$ above the upper sheet. The lower sheet occurs at roughly $50 \% \mathrm{RH}$ point in this transition between the nearly $100 \% \mathrm{RH}$ mass below and the nearly dry air 


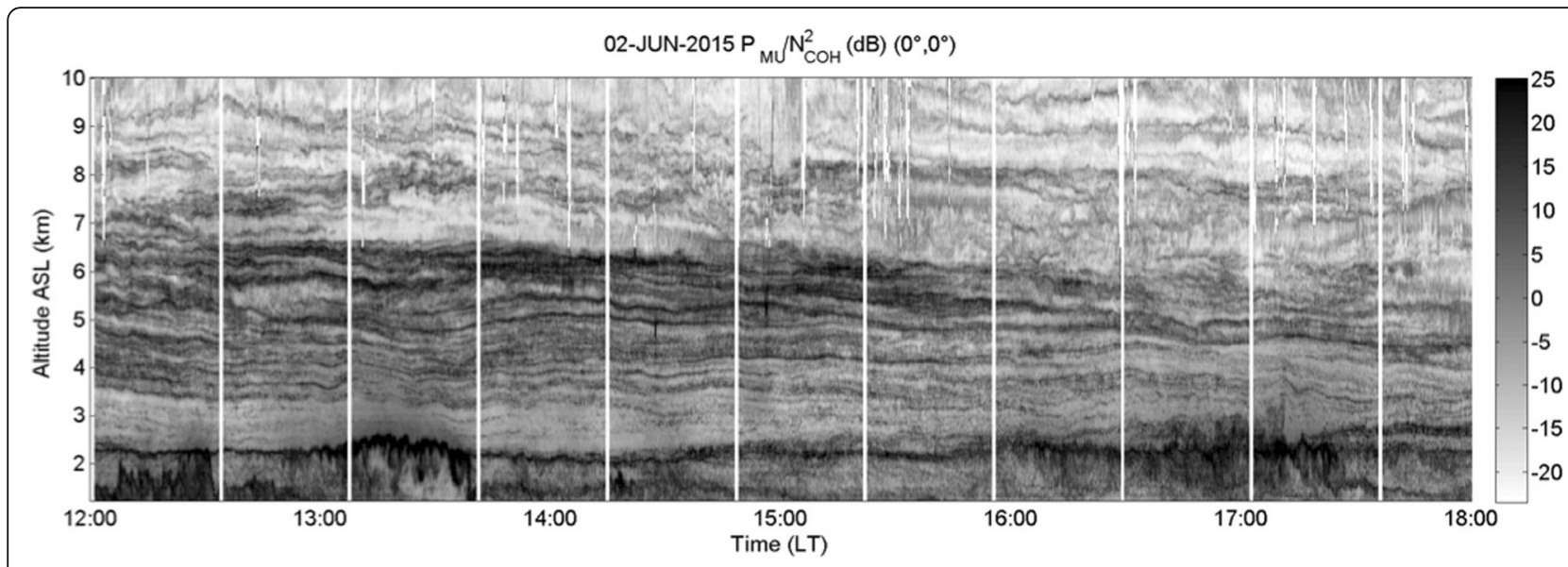

Fig. $1 \mathrm{MU}$ radar echo intensity as a function of altitude (in $\mathrm{km} \mathrm{ASL}$ ) and local time (in hours) on June 2, 2015, from around 12:00 to 18:00 LT during the ShUREX 2015 campaign. The image was processed using the Capon method, with the radar operated in the range-imaging mode on the vertical beam. The scale on the right-hand side is in decibel. The striking feature of this radar image is the appearance of S\&L fine structures which appeared around 09:00, persisting for more than $8 \mathrm{~h}$ till around 17:00 LT. In the lower part, the top of the convective boundary layer, with associated plume activity, can be seen at a height of around $2 \mathrm{~km}$

above. This feature persisted for more than $15 \mathrm{~h}$, with the layer and sheets changing slowly with time. A similar feature was also observed during the 2015 campaign. The resulting elevated radar ducts could have an impact on radar propagation characteristics. The mechanism responsible for the generation of these structures is not known.

\section{Mid-level cloud-base turbulent convective layers}

Figure 3 shows a feature formed by two high humidity gradient sheets, with a turbulent layer in between, evolve into mid-level cloud-base turbulence (MCT) around 15:00 LT on June 13, 2015, during the ShUREX 2015 campaign. The MCT event is triggered by precipitation from within the cloud (hint of which can be seen above the cloud base in the radar image) falling into the dry air below the cloud base, evaporating and triggering instability and strong convection. The dry air layer below the cloud base prior to the MCT event can be seen clearly between 12:00 and 15:00 LT. The top of the MCT layer is the cloud base, and a strong jump in the refractive index gradient occurs there (and also at the bottom of the MCT layer). Such MCT can persist for a few hours, before convection weakens and ceases. MCTs were routinely observed during the 2015 and 2016 campaigns.

Luce et al. (2010) were the first to present evidence of MCT from lidar and MU radar observations, and Kudo (2013) was the very first to investigate MCT as the probable cause of moderate turbulence encountered by pilots around Japan, under certain conditions during summer.

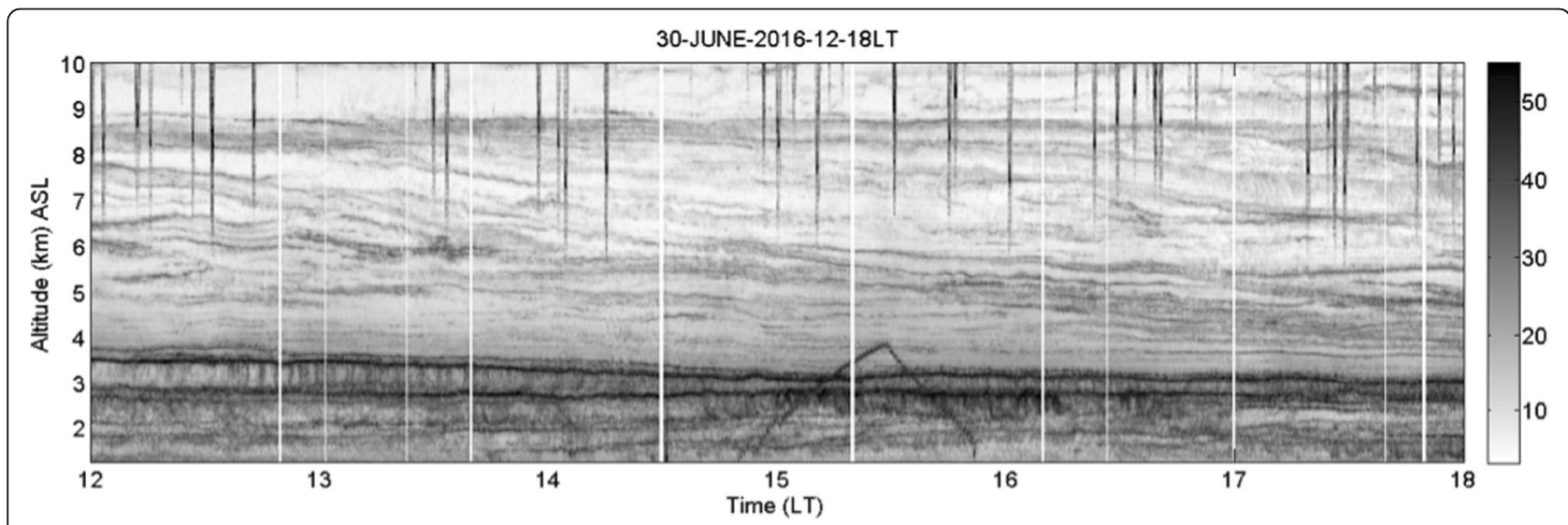

Fig. 2 As in Fig. 1, but on June 30, 2016, from 12:00 to 18:00 LT during the ShUREX 2016 campaign. The striking feature of this radar image is the intrusion of warm, dry air mass over the colder but moist, nearly saturated air adjacent to the ground, leading to the formation of a turbulent "layer" sandwiched between two high humidity gradient "sheets" at the junction of the two air masses at around 3-4 km altitude. The dark vertical lines are commercial aircraft tracks. The inverted V-shaped track in the lower part around 15:30 LT is that of the UAV 


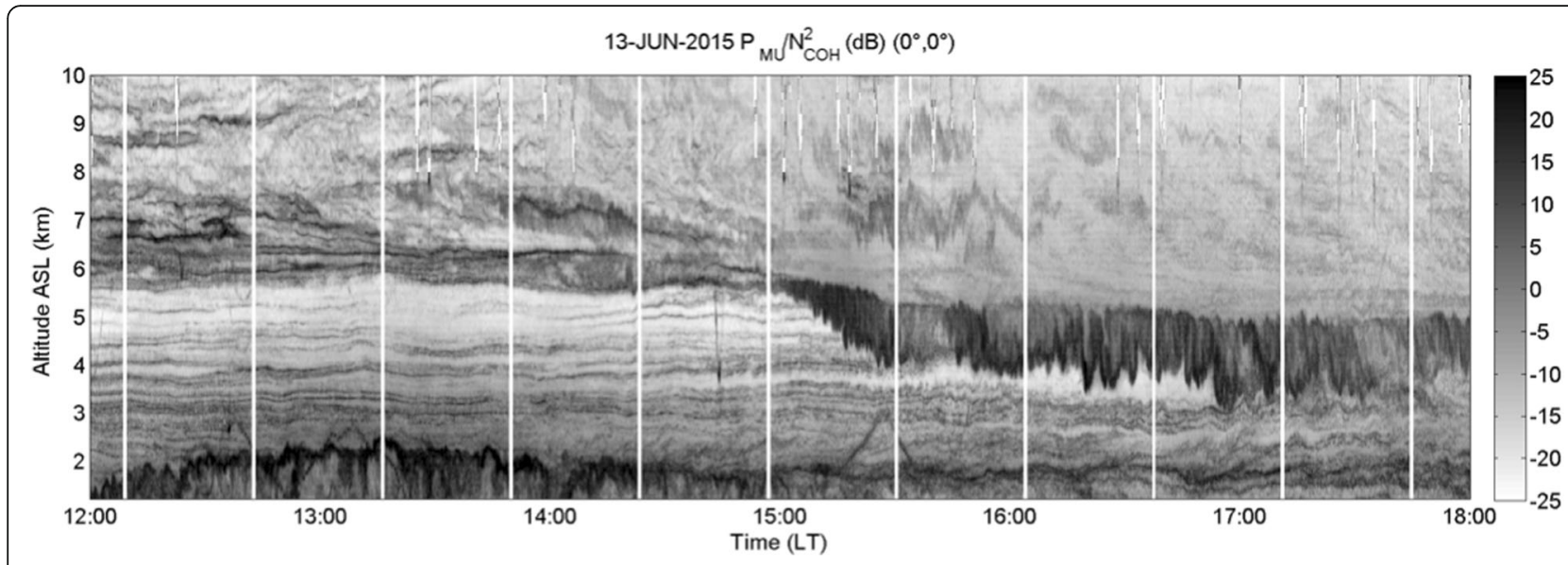

Fig. 3 As in Fig. 1 but from 12:00 to 18:00 LT on June 13, 2015, during the ShUREX 2015 campaign. The layer between the two high humidity gradient sheets evolves into MCT around 15:00 LT, presumably due to precipitation from within the cloud falling into dry air below the cloud base, evaporating and triggering instability and strong convection. The top of the MCT layer is the cloud base, and a strong jump in the refractive index gradient occurs there. CBL with strong convective plume activity penetrating above $2 \mathrm{~km}$ altitude can also be seen between 12:00 and 14:00 LT. Inverted $V$ tracks of the UAV can be seen in and above the CBL

Through numerical simulations, he showed that such turbulence was not caused by shear instability of the Kelvin-Helmholtz type, but it was more likely due to precipitation below the bases of mid-level clouds, which triggered Rayleigh-Taylor instability due to the sublimation of ice/snow particles and consequent cooling of the drier air mass below the cloud base. Kudo et al. (2015) followed up and presented observations of MCT during the Tanuki 2011 campaign at the MU radar site in Shigaraki, Japan, when some radiosondes launched during the campaign managed to sample the MCT, with the MU radar operating simultaneously in a high-resolution mode to provide vivid images of radar backscatter depicting the MCT structure. MU radar measurements of vertical velocities and turbulence kinetic energy (TKE) were presented along with in situ measurements by the sondes, and compared with numerical simulations.

Mid-level cloud-base turbulence (MCT) can occur under synoptic conditions where a moist air mass is advected over a dry one. Around Japan, it occurs typically during the rainy season (Kudo 2013). In spite of the fact that the first article on MCT was published in 2010 (Luce et al. 2010) and was followed up by Kudo (2013), Wilson et al. (2014), and Kudo et al. (2015), very little additional work has been done on MCT until Kantha et al. (2019) cataloged and presented MCT events observed during the 2015 and 2016 campaigns. They also present a one-dimensional, second moment closure-based model of turbulent mixing in the MCT layer, with the event observed on June 13, 2015 (Fig. 3) used as an example.

\section{Kelvin-Helmholtz instability and billow structures}

A principal mechanism for generation of turbulence in a stably stratified fluid column is shear instability. When the governing gradient Richardson number falls below a value of around 0.25 , Kelvin-Helmholtz $(\mathrm{KH})$ instability occurs with ensuing billow-like structures, which almost always dissolve into fully developed turbulence. $\mathrm{KH}$ instability (KHI) and $\mathrm{KH}$ billows were seen frequently during the ShUREX campaigns. Figure 4 shows a textbook example of $\mathrm{KH}$ billows generated inside the mid-level cloud just above the cloud base at around 14:40 LT, with MCT occurring concurrently below the cloud base. A similar event that occurred on June 11, 2015, was analyzed and discussed in detail by Luce et al. (2018d).

The decay of MCT was often accompanied by small-scale KHI activity at the cloud base. Examples of this can be seen in Fig. 4 at 16:50 and 17:40 LT.

\section{Convective boundary layer}

On several days during the campaigns, the solar heating was strong enough to generate vigorous convective activity in the planetary boundary layer. One example of that is shown in Fig. 5, where the top of the CBL has reached just beyond $2 \mathrm{~km}$ altitude. It was possible for the UAV to probe that CBL. UAV tracks can be seen as thin lines.

\section{Sheet and layer (S\&L) structures}

Most often, the atmospheric column displayed very stable and persistent S\&L structures, with little turbulence activity apparent. This was especially true of the 2017 campaign, when the onset of the rainy season was delayed. One such example can be seen in Fig. 5. The S\&L structures were made visible by the high radar reflectivity of the high humidity gradient sheets. Such structures were very persistent and often lasted for more than 24-48 h. Turbulence, if any, in faint layers between 


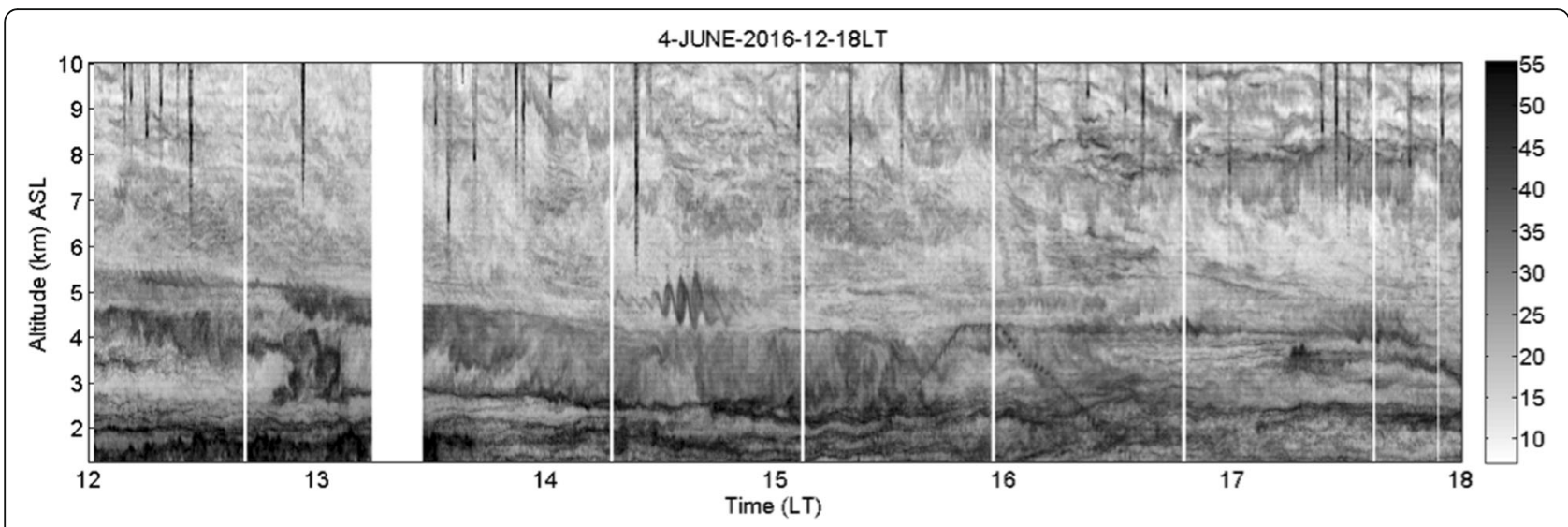

Fig. 4 As in Fig. 1 but from 12:00 to 18:00 LT on June 4, 2016 during the ShUREX 2016 campaign. High amplitude KH billows can be seen at an altitude of around $5 \mathrm{~km}$ from 14:30 to 14:50 LT, inside but just above the cloud base, with MCT occurring concurrently just below the cloud base. Dark thin lines around 16:00 LT denote the UAV track. Small scale KHI activity can be seen at around 16:50 and 17:40 LT

the dark sheets could not be reliably measured by sensors on board the UAVs. The mechanism causing and maintaining such S\&L structures and the degree of impact on atmospheric dynamics are not clear to us. Chuda et al. (2007) have advanced a plausible mechanism for S\&L structures seen in radiosonde profiles, but it is not clear if it is applicable to at least some of the S\&L fine structures observed in the high-resolution radar images during the ShUREX campaigns. Clearly, more studies are needed.

\section{Structures with wave-like oscillations}

On one occasion during the three campaigns, on June 9, 2015 (Fig. 6), we saw a strong MCT occur below the cloud base located at $5-6 \mathrm{~km}$ altitude (ASL). The lower edge of the MCT layer (dark region with vertical striations) was located between 3.5 and $4.5 \mathrm{~km}$, with prominent indentations created by convective plume activity inside the MCT layer. Perhaps due to appropriate stable stratification below the cloud base, these indentations produced wave-like structures in the atmospheric column beneath the MCT layer down to $1.34 \mathrm{~km}$ (ASL). These wave-like oscillations probably extended all the way to the ground, but the radar is unable to see below $1.34 \mathrm{~km}$. These structures appear to be phase-locked with indentations at the lower edge of the MCT layer caused by vigorous convective plume activity inside the MCT layer. The period of the oscillations ranges between 4 and $8 \mathrm{~min}$. It appears that these are forced oscillations produced by strong convective plume activity inside the MCT. This phenomenon requires further study.

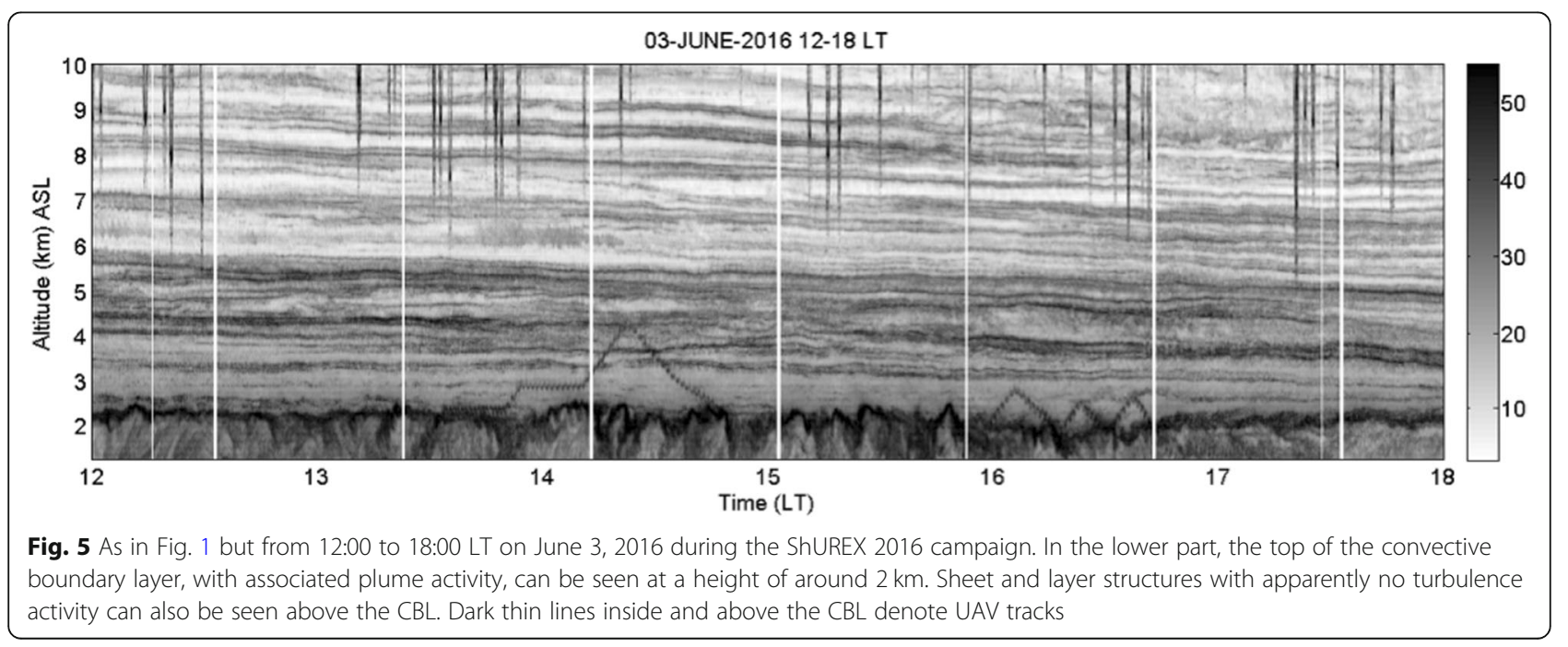




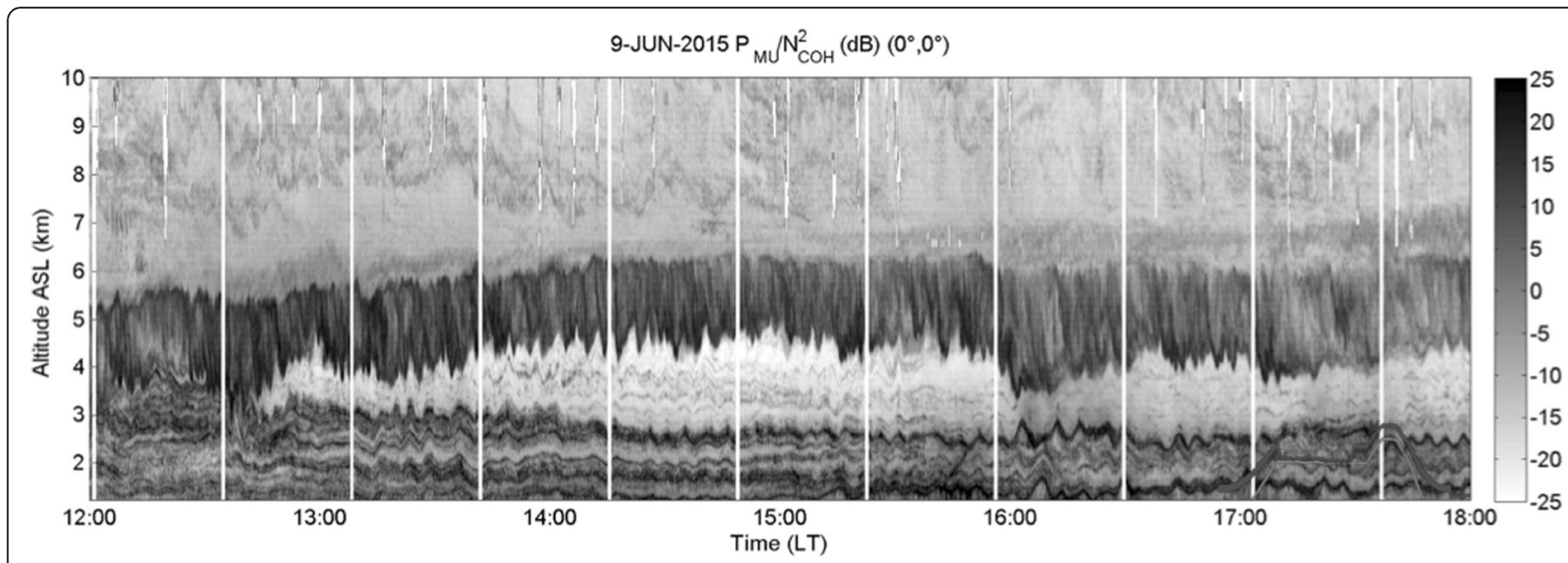

Fig. 6 As in Fig. 1 but from 12:00 to 18:00 LT on June 9, 2015, during the ShUREX 2015 campaign. A strong MCT event with the cloud base around 5-6 km altitude (ASL) can be seen. This was the only occasion during all three campaigns, when wave-like structures were observed in the MU radar image (between 12:30 and 18:00 LT at altitudes between $1.4 \mathrm{~km}$ and the bottom of the MCT layer). The apparent period is 4 to 8 min. The lines between 17:00 and 18:00 LT denote UAV tracks

\section{Conclusions}

The high-resolution Capon images from the MU radar, operated in range-imaging mode (Luce et al. 2001, Luce et al. 2010, Luce et al. 2018a) during the ShUREX campaigns revealed a variety of atmospheric structures in great detail. It was also possible to see their evolution in time. We have presented and discussed some examples of such structures of potential importance to atmospheric dynamics. However, it is best to see videos of the radar images to appreciate the evolution of these features. As such, we have presented three videos as Additional files 1, 2 and 3, with a brief explanatory text as Additional file 4 It is our hope that these videos persuade ST radar operators around the world to implement range-imaging mode of operation on at least the vertical beam of their radars, so that it is possible to visualize the evolution of atmospheric features above those radars.

\section{Additional files}

Additional file 1: Videos of atmospheric structures observed during ShUREX 2015 and 2016. (MOV $1230 \mathrm{~kb}$ )

Additional file 2: Videos of atmospheric structures observed during ShUREX 2015 and 2016. (MOV $9480 \mathrm{~kb}$ )

Additional file 3: Videos of atmospheric structures observed during ShUREX 2015 and 2016. (MOV $1350 \mathrm{~kb}$ )

Additional file 4: Supplementary text. (DOCX $32 \mathrm{~kb}$ )

\section{Abbreviations}

ASL: Above sea level; CBL: Convective boundary layer; KH: Kelvin-Helmholtz; MCT: Mid-level cloud-base turbulence; MU: Middle and Upper atmosphere; RH: Relative humidity; RISH: Research Institute for Sustainable Humanosphere; S\&L: Sheet and layer; ShUREX: Shigaraki UAV Radar Experiment; SNR: Signal to noise ratio; ST: Stratosphere troposphere; UAV: Unmanned aerial vehicle; VHF: Very high frequency

\section{Acknowledgements}

LK thanks the Japanese Society for Promotion of Science (JSPS) for providing partial funding for the ShUREX 2016 campaign. The hospitality of RISH personnel and director Prof. Tsuda to their visitors is exemplary.

\section{Funding}

This study was supported by JSPS KAKENHI Grant Number JP15K13568 and the research grant for Mission Research on Sustainable Humanosphere from Research Institute for Sustainable Humanosphere (RISH), Kyoto University. The MU radar belongs to and is operated by RISH, Kyoto University.

\section{Availability of data and materials}

MU radar images are available on RISH website as indicated in Additional file 1.

\section{Authors' contributions}

$\mathrm{HL}$ collected and analyzed the MU radar data and assisted LK in the interpretation of the structures revealed. LK organized and participated in the ShUREX campaigns. HH oversaw the ShUREX campaigns. AD produced the videos from Capon images. All authors read and approved the final manuscript.

\section{Authors' information}

LK is a professor in the Department of Aerospace Engineering Sciences at the University of Colorado, Boulder, USA. HL is an associate professor at Universite de Toulon, Toulon, France. $\mathrm{HH}$ is a professor at RISH, Kyoto University, Uji, Japan. AD is a graduate student at the University of Colorado, Boulder, USA.

\section{Competing interests}

The authors declare that they have no competing interests.

\section{Publisher's note}

Springer Nature remains neutral with regard to jurisdictional claims in published maps and institutional affiliations.

\section{Author details}

'Department of Aerospace Engineering Sciences, University of Colorado, Boulder, CO, USA. ${ }^{2}$ Mediterranean Institute of Oceanography, Université de Toulon, UMR 7294 La Garde, France. ${ }^{3}$ Research Institute for Sustainable Humanosphere, Kyoto University, Kyoto, Japan. 
Received: 1 November 2018 Accepted: 22 February 2019

Published online: 29 March 2019

\section{References}

Chuda T, Kimura R, Niino H (2007) Vertical fine structures of temperature and water vapor in the free atmosphere. J Meteo Soc Japan 85:583-597

Kantha L, Lawrence D, Luce H, Hashiguchi H, Tsuda T, Wilson R, Mixa T, Yabuki M (2017) Shigaraki UAV-Radar Experiment (ShUREX): overview of the campaign with some preliminary results. Prog Earth Planet Sci 4:19. https://doi.org/10. 1186/s40645-017-0133-x

Kantha L, Luce H, Hashiguchi H (2019) Mid-level cloud-base turbulence: radar observations and models. J Geophys Res Atmos. https://doi.org/10.1029/ 2018JD029479

Kudo A (2013) The generation of turbulence below midlevel cloud bases: the effect of cooling due to sublimation of snow. J Appl Meteorol 52:819-833. https://doi.org/10.1175/JAMC-D-12-0232.1

Kudo A, Luce H, Hashiguchi H, Wilson R (2015) Convective instability underneath midlevel clouds: comparisons between numerical simulations and VHF radar observations. J Appl Meteorol 54:2217-2227. https://doi.org/10.1175/JAMC-D15-0101.1

Luce H, Hashiguchi H, Kantha L, Lawrence D, Tsuda T, Mixa T, Yabuki M (2018a) On the performance of the range imaging technique estimated using unmanned aerial vehicles during the ShUREX 2015 campaign. IEEE Trans Geosci Remote Sensing 56. https://doi.org/10.1109/TGRS.2017.2772351.

Luce H, Kantha L, Hashiguchi H, Lawrence D, Yabuki M, Tsuda T, Mixa T (2018b) Comparisons between high-resolution profiles of squared refractive index gradient $\mathrm{M}^{2}$ measured by the Middle and Upper Atmosphere Radar and unmanned aerial vehicles (UAVs) during the Shigaraki UAV-Radar Experiment 2015 campaign. Ann Geophys 35:423-441. https://doi.org/10.5194/angeo-35423-2017

Luce H, Kantha L, Hashiguchi H, Lawrence D, Mixa T, Yabuki M, Tsuda T (2018c) Vertical structure of the lower troposphere derived from MU radar, unmanned aerial vehicle, and balloon measurements during ShUREX 2015. Prog Earth Planet Sci 5:29. https://doi.org/10.1186/s40645-018-0187-4.

Luce H, Kantha L, Yabuki M, Hashiguchi H (2018d) Atmospheric Kelvin-Helmholtz billows captured by the MU radar, lidars and a fish-eye camera. Earth Planets Space 70:162. https://doi.org/10.1186/s40623-018-0935-0 (MST 15 Radar Workshop Special Issue).

Luce H, Nakamura T, Yamamoto MK, Yamamoto M, Fukao S (2010) MU radar and lidar observations of clear-air turbulence underneath cirrus. Mon Wea Rev 138:438-452. https://doi.org/10.1175/2009MWR2927.1

Luce H, Yamamoto M, Fukao S, Helal D, Crochet M (2001) A frequency domain radar interferometric imaging (FII) technique based on high-resolution methods. J Atmos Solar-Terrestrial Phys 63:221-234

Wilson R, Luce H, Hashiguchi H, Nishi N, Yabuki M (2014) Energetics of persistent turbulent layers underneath mid-level clouds estimated from concurrent radar and radiosonde data. J Atmos Sol-Terr Ph 118:78-89

\section{Submit your manuscript to a SpringerOpen ${ }^{\odot}$ journal and benefit from:}

- Convenient online submission

- Rigorous peer review

- Open access: articles freely available online

- High visibility within the field

- Retaining the copyright to your article

Submit your next manuscript at $\boldsymbol{\nabla}$ springeropen.com 